in vivo $35: 2631-2640(2021)$

doi:10.21873/invivo.12545

\title{
The Expression of NRIP1 and LCOR in Endometrioid Endometrial Cancer
}

\author{
STEFANOS FLINDRIS ${ }^{1}$, NIKOLAOS KATSOULAS ${ }^{2}$, ANNA GOUSSIA ${ }^{3}$, ANDREAS CHRISTOS LAZARIS ${ }^{2}$, \\ IORDANIS NAVROZOGLOU ${ }^{1}$, MINAS PASCHOPOULOS ${ }^{1}$ and IRENE THYMARA ${ }^{2}$ \\ ${ }^{1}$ Department of Obstetrics and Gynecology, University Hospital of Ioannina, Ioannina, Greece; \\ ${ }^{2}$ First Department of Pathology, School of Medicine, National and Kapodistrian University of Athens, \\ Laiko General Hospital of Athens, Athens, Greece; \\ ${ }^{3}$ Department of Pathology, University Hospital of Ioannina, Ioannina, Greece
}

\begin{abstract}
Background: The aim of the study was to analyze the expression of nuclear receptor interacting protein 1 (NRIP1) and its partner ligand-dependent nuclear receptor co-repressor (LCOR) in endometrioid endometrial cancer and to investigate their association with estrogen receptor (ER), progesterone receptor (PR), Ki-67, clinicopathological parameters and patient survival. Materials and Methods: Immunohistochemical evaluation was carried out to investigate the subcellular expression of NRIPI and LCOR in endometrioid endometrial cancer samples. Statistical analysis was used to identify the correlations of NRIPI and LCOR expression with clinicopathological variables and to estimate the survival rates. Results: Endometrial cancer tissues exhibited higher expression of NRIP1 and LCOR in comparison with the normal tissues. Cytoplasmic LCOR expression was positively associated with ER and PR expression, while cytoplasmic NRIP1 expression was positively associated with ER expression. Moreover, cytoplasmic expression of NRIP1 was positively associated with Ki-67. Conclusion: Our study demonstrated that high cytoplasmic expression of LCOR may predict a longer overall survival of patients with endometrioid endometrial cancer. Patients with tumors expressing low levels of LCOR showed a worse survival compared to those expressing high levels.
\end{abstract}

This article is freely accessible online.

Correspondence to: Stefanos Flindris (ORCID: 0000-0002-23613470), MD, Resident in Obstetrics and Gynecology, University Hospital of Ioannina, Stavros Niarchos Avenue, 45500 Ioannina, Greece. Mobile: +30 6957342754, e-mail: stefflindris@gmail.com

Key Words: Endometrioid endometrial cancer, NRIP1, LCOR, ER, PR.
Endometrial cancer is the sixth most common cancer among females worldwide and the fourth leading cause of cancer (1). It is considered as the most common gynecological malignancy, accounting for $7 \%$ of all female cancer (1). Two broad pathogenetic types of endometrial carcinoma have been recognized: Type I tumors are endometrioid carcinomas and type II are non-endometrioid, including serous and clearcell carcinomas (2). Most cases (90\%) of endometrial carcinomas occur in women older than 50 years of age, with a median age of 62 years at diagnosis, and are detected in early stages [ $80 \%$ in International Federation of Obstetrics and Gynecology (FIGO) stage I] $(2,3)$.

Recent studies have focused on the involvement of nuclear receptor interacting protein 1 (NRIP1/RIP140) and Liganddependent nuclear receptor co-repressor (LCOR) in tumor development through complex regulation of pathogenetic pathways (4). NRIP1 is a co-regulator which consists of four inhibitory domains that recruit $C$-terminal binding proteins, and one of histone deacetylase (HDAC) (5-8). It acts primarily as a co-repressor through binding to nuclear receptors of other co-factors in a ligand-dependent manner to limit their transactivation (9-12). Intriguingly, NRIP1 interacts with E2F transcription factors, suppressing their transcriptional function and also suppresses proliferator activated receptor gamma (PPARG) through receptor coactivator 1 (NCOA1), thereby inhibiting cell proliferation (13). This kind of dysregulation may affect other signaling pathways, such as NOTCH, p53, Hedgehog and Hippo, resulting in up-regulation of their expression on cancer cells (14). According to many studies, NRIP1 is engaged in the development and progression of solid tumors (15-18). Ferreira et al. showed that NRIP1 to be the most frequently mutated gene in endometrial cancer cell lines and to be associated with microsatellite instability, dysregulating the gene expression of estrogen receptor (ER) pathway (19). NRIP1 is considered an essential transcriptional co-factor for estrogen signaling $(11,20)$. It has been found that it interacts 
mainly with ER $\beta$ and may also act as a tumor suppressor in ovarian and colonic cancer $(14,21)$. Specifically, in ovarian cancer NRIP1 may be involved in the suppression of ER $\alpha$ activity through ER $\beta$ (21). In colonic cancer, NRIP1 has a negative effect on the WNT signaling pathway by reducing gene expression and thereby inhibiting colonic cancer cell proliferation (14). Similarly, high expression of NRIP1 in chronic lymphocytic leukemia has a favorable prognostic significance (15). Importantly, the NRIP1 expression level was higher in the nucleus of breast cancer cells, whereas it was higher in the cytoplasm of stromal cells in benign tumors $(10,22)$.

Another transcriptional co-repressor, LCOR functions similarly to the aforementioned mechanisms of NRIP1, using $C$-terminal binding proteins and HDAC domains (8, 23). Several studies demonstrated that NRIP1 and LCOR may play a key role in tumorigenesis $(14,24-26)$. It has been shown that NRIP1 directly interacts with LCOR, and that both proteins co-localize in the nucleus of human breast cancer cells (24). The physiological role of LCOR is poorly understood, although it may participate in homeostasis of liver and in prostate cancer $(27,28)$. Of importance, LCOR interacts with $\mathrm{ER} \alpha$ and drives repressive activity in breast cancer cells $(8,11)$. In breast cancer cells, proliferation is suppressed by LCOR through down-regulation of gene expression mediated by estrogens (22). This is the result of the strong regulation of LCOR expression by NRIP1 (11). Interestingly, LCOR interacts with a subunit of tripartite motif containing 28 (TRM28), kruppel-like factor 6 (KLF6) and PPARG $(29,30)$. Moreover, NRIP1 and LCOR act synergistically, recruiting co-factors involved in transcriptional co-repression or recognizing the same coactivator binding domains in ligand binding domains of nuclear receptors $(24,26)$. In cervical cancer, low levels of NRIP1 and LCOR are associated with better survival outcome (25). Furthermore, LCOR was found to be an attenuator of progesterone-regulated gene expression in breast cancer, and inhibits prostate cancer growth through co-repression of activated androgen receptor in murine models $(23,27)$. Other studies demonstrated the relevance of LCOR with inhibition of mammary cancer cell activity $(23,27,31)$.

Conducting this retrospective study, we aimed to examine the specific role of nuclear and cytoplasmic NRIP1 and LCOR expression in endometrial cancer type I. To our knowledge there are no data about the expression of NRIP1 and LCOR in endometrial carcinomas in the international literature. For this purpose, we analyzed the immunohistochemical expression of NRIP1 and LCOR in a cohort of 93 patients who had undergone total or radical hysterectomy for endometrioid endometrial cancer and evaluated the correlation between their expression and clinicopathological features, as well as with patient outcomes.

\section{Materials and Methods}

Patient characteristics. Representative paraffin-embedded tissue samples were selected from 93 patients with endometrioid endometrial carcinoma, who were treated with total or radical (when appropriate) hysterectomy and bilateral salgingo-ophorectomy at the Department of Obstetrics and Gynecology, University Hospital of Ioannina, Ioannina Greece during the period of 2008-2015. All tumors were classified using the 2018 FIGO classification (IA-B II, IIIA-B/C1-2, IVA-B) (32), myometrial invasion and the presence or absence of metastases was determined by computed tomography (33). Patient data, such as age, pathology reports, status of metastasis, local recurrence, record of adjuvant therapy after surgery, radiotherapy treatment and outcome were retrieved from the clinical database of the Departments of Pathology and Obstetrics and Gynecology of University Hospital of Ioannina, Ioannina, Greece. In order to compare our findings with normal tissues, samples were collected from 23 patients who had undergone total hysterectomy for benign uterine tumors (leiomyomas). All patient data were fully anonymized, and all diagnostic procedures had already been fully completed when samples were collected for the study. Authors were blinded from the clinical information during the experimental analysis. The study was approved by the Ethics Committee of the National and Kapodistrian University of Athens, Athens, Greece (approval number 095, 25/02/2019).

Immunohistochemical analysis. Formalin-fixed paraffin-embedded tissue sections were retrieved from the Department of Pathology, University of Ioannina, Ioannina, Greece. A hematoxylin-eosin evaluation round was employed for obtaining representative tissue samples for immunohistochemical analysis. Immunohistochemistry was performed on $2.5 \mu$ m-thick tissue sections, which were consecutively incubated with the following primary antibodies to NRIP1 (HPA046571, 1:400 in phosphate-buffered saline polyclonal rabbit IgG; Sigma Aldrich, St. Louis, MO, USA) and anti-LCOR (C6) sc-377019 (1:200 in phosphate-buffered saline mouse polyclonal IgG; Santa Cruz Biotechnology, Dallas, TX, USA). The staining procedures were performed by the avidin-biotin technique using LSAB2 System-HRP (Dako Omnis, Glostrup, Denmark). Appropriate tissues (placenta and salpinx) were used as positive controls, while omission of primary antibodies was used as a negative control. For all tumor cases, immunostaining of ER, progesterone receptor (PR) and $\mathrm{Ki}-67$ proteins was performed by using antibodies to ER (6F11, 1:40 in phosphate-buffered saline mouse monoclonal IgG1; Leica Biosystems Newcastle, Newcastle Upon Tyne, UK), PR (686, 1:150 in phosphate-buffered saline mouse monoclonal IgG1; Dako Omnis) and anti-Ki-67 M7240 (1:150 mouse monoclonal IgG1; Dako Omnis). All tissue slides were reviewed by two experienced pathologists using a digital microscope (Nikon Eclipse 80; Nikon, Tokyo, Japan) whilst blinded to patient clinicopathological and survival data. Images were captured using appropriate software (CellSens Entry Imagine Software, Olympus, Tokyo, Japan).

In order to differentiate the distribution and intensity patterns for LCOR, NRIP1 as well as ER, PR and Ki-67, in our endometrial cancer tissues, the semi-quantitative immunoreactive score (IRS) was used. The IRS assessed the percentage of positively stained cells ( $0=$ no staining, $1 \leq 10 \%$ of cells, $2=11-50 \%$ of cells, $3=51-80 \%$, and $4 \leq 81 \%$ of cells) multiplying the score by the intensity of cell staining (graded as $0=$ none, $1=$ weak, $2=$ moderate, and $3=$ strong). Therefore, the maximum IRS score was 12 . Two independent 
examiners evaluated doubtful cases, and the final IRS was assigned by consensus $(24,25)$.

Statistical analysis. The correlations presented were obtained by calculating Spearman's rho correlation coefficient (Q). MannWhitney $U$ non-parametric test was used to detect significant differences between two groups, whilst Kruskal-Wallis H nonparametric test was used to detect significant differences between three or more groups. Patients were monitored for a period of 60 months from the time of surgery. For comparison of survival, Kaplan-Meier curves were generated, and Mantel-Cox (log-rank) test was performed to compare survival curves. Multivariate forward likelihood ratio Cox regression analysis was also performed to test which histopathological variables out of age, FIGO classification, differentiation grade, myometrial invasion and IRS scores for cytoplasmic LCoR, cytoplasmic NRIP1, nuclear NRIP1, Ki67, PR and ER were independent prognosticators for overall survival (OS). Additionally, for the current study, the ideal cut-off values for assigning patients to groups with low and high NRIP1 and LCOR IRS scores were determined by receiver operating characteristic curve analysis in accordance with maximal differences of specificity and sensitivity (25). Statistical analysis was performed using SPSS 21 (IBM-SPSS Statistics, IBM Corp., Armonk, NY, USA). The level of statistical significance was set to $5 \%(p=0.05)$.

\section{Results}

Patient and tumor characteristics. For the entire cohort, the median age of the patients was 64 years (mean \pm standard deviation $=64 \pm 8.5$ years, range $=43-82$ years ). The follow-up of patients was at least 5 years. In our study, most tumors were FIGO stage I and II (86\%); the basic tumor characteristics are shown in Table I.

Immunohistochemical analysis of NRIPI and LCOR protein expression. Cytoplasmic LCOR and nuclear and cytoplasmic NRIP1 IRS were evaluated in all studied cases. The IRS values were higher in carcinomas compared to control tissues for cytoplasmic LCOR (median IRS 1.0 and 0.0 for cancer and control tissues, respectively, $\mathrm{U}=486, p<0.0001$ ), nuclear NRIP1 (median IRS 1.0 and 0.0 for cancer and control tissues respectively, $\mathrm{U}=806, p=0.046$ ) and cytoplasmic NRIP1 (median IRS 2.0 and 0.0 for cancer and control tissues, respectively, $\mathrm{U}=701, p=0.008$ ). A slight positivity of NRIP1 expression was observed not only in cancer tissue, but also in some stromal cells of the endometrium (Figure 1).

Correlations of LCOR and NRIP1 protein expression with clinicopathological parameters. Spearman's Q correlation test was applied for the analysis of correlation of LCOR and NRIP1 IRS with other parameters i.e., patient age, Ki-67, PR and ER IRS. The analysis showed that the IRS for cytoplasmic LCOR was positively correlated with that for ER (Spearman's $\varrho=0.351, p=0.001$ ) and PR (Spearman's $\varrho=0.289, p=0.005$ ). The IRS for cytoplasmic NRIP1 was positively correlated with that for nuclear NRIP1 (Spearman's $Q=0.481, p<0.0001$ ), ER
Table I. Descriptive table of clinicopathological characteristics of study patients ( $n=93)$.

\begin{tabular}{lcc}
\hline Characteristic & Subgroup & Frequency \\
\hline FIGO stage & I & $56(60.2 \%)$ \\
& II & $24(25.8 \%)$ \\
& III & $10(10.8 \%)$ \\
Grade & IV & $3(3.2 \%)$ \\
& 1 & $29(31.2 \%)$ \\
Myometrial invasion & 2 & $50(53.8 \%)$ \\
& 3 & $14(15.1 \%)$ \\
ER & $<50 \%$ & $44(47.3 \%)$ \\
& $>50 \%$ & $49(52.7 \%)$ \\
PR & Negative & $14(15.1 \%)$ \\
& Positive & $79(84.9 \%)$ \\
Ki-67 & Negative & $8(8.6 \%)$ \\
Cytoplasmic LCOR & Positive & $85(91.4 \%)$ \\
& Negative & $8(8.6 \%)$ \\
NRIP1 & Positive & $85(91.4 \%)$ \\
Nuclear & Negative & $38(40.9 \%)$ \\
& Positive & $55(59.1 \%)$ \\
Cytoplasmic & Negative & $46(49.5 \%)$ \\
& Positive & $47(50.5 \%)$ \\
& Negative & $32(34.4 \%)$ \\
& Positive & $61(65.6 \%)$ \\
\hline
\end{tabular}

ER: Estrogen receptor; FIGO: International Federation of Obstetrics and Gynecology; Ki-67: proliferative marker Ki-67; LCOR: liganddependent nuclear receptor corepressor; NRIP1: nuclear receptor interacting protein 1 ; PR: progesterone receptor.

(Spearman's $\varrho=0.328, p=0.001$ ) and Ki-67 (Spearman's $\mathrm{Q}=0.464, p<0.0001)$. Age was not correlated with cytoplasmic LCOR IRS nor with nuclear or cytoplasmic NRIP1 IRS ( $p>0.05$ for all three scores) (Table II).

The associations between the depth of myometrial invasion (patients with $50 \%$ or more $v s$. patients with less than $50 \%$ ) and the expression of the studied proteins were tested with Mann-Whitney $U$-test. Myometrial invasion was correlated statistically significantly with nuclear NRIP1 IRS ( $\mathrm{U}=716, p=0.004)$ and cytoplasmic NRIP1 IRS (U=755.50, $p=0.012$ ). Specifically, both nuclear and cytoplasmic NRIP1 IRS were higher in tumors invading $50 \%$ or more of the myometrium than those invading less than half (Table III). However, myometrial invasion was not correlated with cytoplasmic LCOR IRS ( $\mathrm{U}=1040, p=0.896$ ).

Significant differences between LCOR cytoplasmic, NRIP1 nuclear, NRIP1 cytoplasmic IRS scores, grade and FIGO stage were tested with Kruskal Wallis H- test. The cytoplasmic LCOR IRS was correlated statistically significantly with tumor grade $(p=0.021)$ as higher grades were associated with lower cytoplasmic LCOR IRS (Table IV and Figure 2). In contrast, nuclear and cytoplasmic NRIP1 IRS did not show any statistical correlation with 

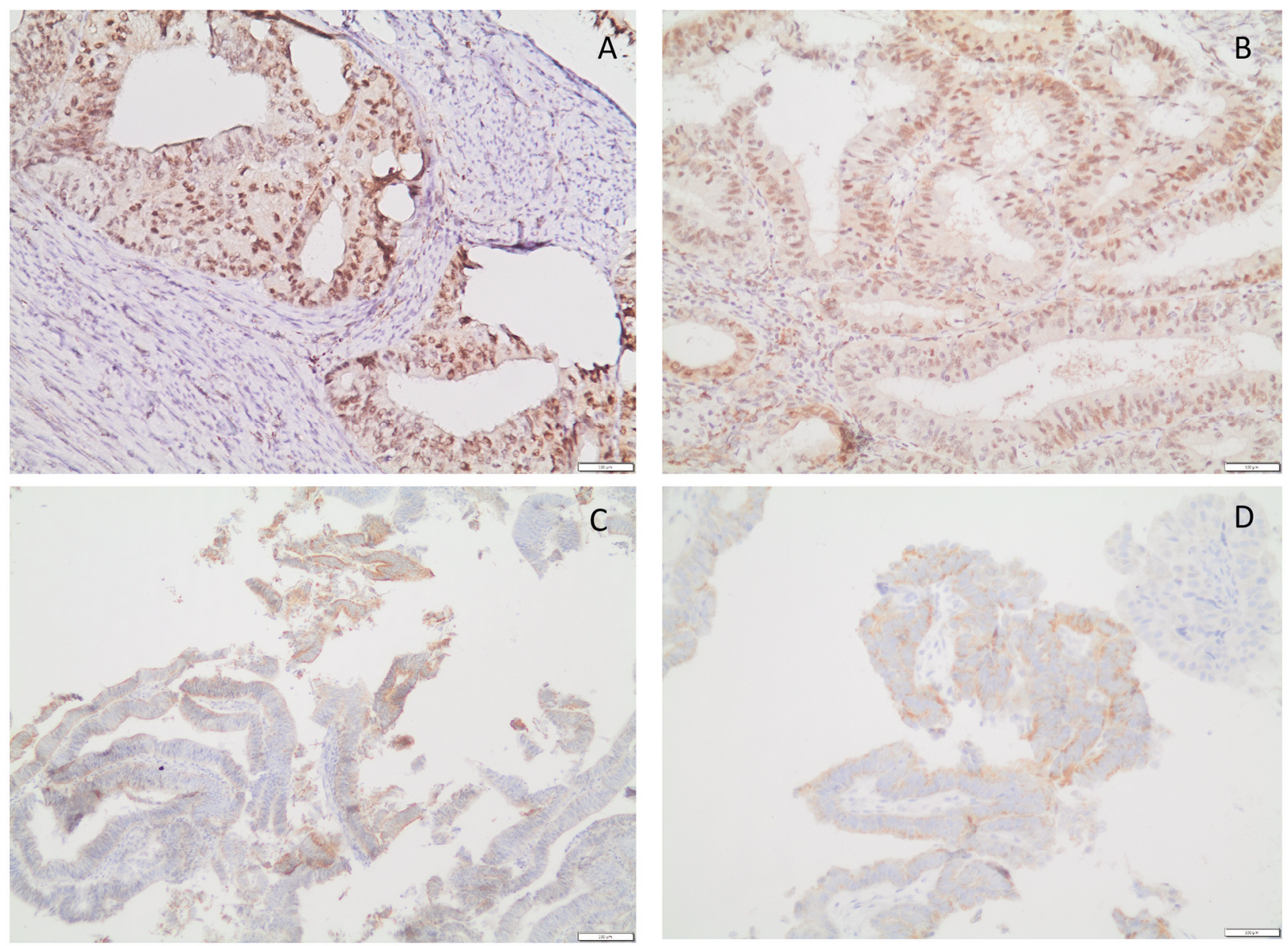

Figure 1. A and B: Representative immunohistochemical staining of nuclear receptor interacting protein (NRIP1) in endometrioid endometrial cancer: High immunohistochemical expression of NRIP1 in both the nucleus and cytoplasm is apparent. Slight immunohistochemical positivity of NRIP1 in stromal cells is also demonstrated (original magnification: $\times 200$ ). C and D: Immunohistochemical staining for ligand-dependent corepressor (LCOR) in endometrioid endometrial cancer; high expression is depicted. In our study, LCOR was expressed only in the cytoplasm of cancer cells (original magnification: $C \times 100$ and D×200).

grade ( $p=0.902$ and $p=0.509$, respectively). No significant differences were found according to FIGO stage $(p>0.05$ for all protein scores) (Table IV).

Correlations with patient survival. For this analysis, patients were categorized based on IRS for LCOR and NRIP1. Optimized IRS cut-off values were used (IRS $\leq 2$ for low expression and IRS $>2$ for high expression) $(24,25)$. OS for patients with cancer with low expression was compared with those with high expression using Kaplan-Meier analyses with log-rank test (Table V). Patients with low cytoplasmic LCOR expression had a significantly worse OS than those with high expression (mean OS $47.6 \pm 2.2$ vs. $52.8 \pm 2.9$ months, $p=0.029$ ) (Figure 3 and Table V). However, OS was not significantly correlated with nuclear or cytoplasmic NRIP1 IRS ( $p=0.502$ and $p=0.452$, respectively) (Table V).
Multivariate Cox regression analysis was performed to test which histopathological variables were independent prognosticators for patient survival (Table VI). Cytoplasmic LCOR IRS score $(p=0.003)$, ER IRS $(p=0.014)$, FIGO stage $(p=0.004)$ and tumor grade $(p=0.001)$ were independent prognosticators for patient survival. The risk of death was reduced by $34.8 \%$ for each unit increase of cytoplasmic LCOR IRS $(\operatorname{Exp}(B)=0.652$, $p=0.003$ ). The hazard ratio increased by a factor 1.17 of for each unit increase of ER IRS $(p=0.014)$. Patients with FIGO stage III had a 2.65 -fold increased probability of not surviving compared to those with stage I $(p=0.043)$. Patients with grade 3 tumor had 4.3-fold increased probability of not surviving compared to grade 1 $(p=0.007)$. No significant effect was seen for the other variables $(p>0.05)$. 
Table II. Spearman's rho (@) correlation analysis.

\begin{tabular}{|c|c|c|c|c|c|c|c|}
\hline \multirow[b]{2}{*}{ Protein } & & \multicolumn{2}{|c|}{ NRIP1 } & \multirow{2}{*}{$\frac{\text { ER }}{\text { Nuclear }}$} & \multirow{2}{*}{$\frac{\mathrm{PR}}{\text { Nuclear }}$} & \multirow{2}{*}{$\frac{\text { Ki-67 }}{\text { Nuclear }}$} & \multirow[b]{2}{*}{ Age } \\
\hline & & Nuclear & Cytoplasmic & & & & \\
\hline \multirow[t]{2}{*}{ LCOR, cytoplasmic } & $\varrho$ & 0.162 & 0.183 & 0.351 & 0.289 & 0.077 & 0.01 \\
\hline & $p$-Value & 0.121 & 0.079 & 0.001 & 0.005 & 0.461 & 0.92 \\
\hline \multicolumn{8}{|l|}{ NRIP1 } \\
\hline \multirow[t]{2}{*}{ Nuclear } & $\varrho$ & & 0.481 & 0.133 & -0.025 & 0.171 & 0.03 \\
\hline & $p$-Value & & $<0.0001$ & 0.202 & 0.811 & 0.101 & 0.79 \\
\hline \multirow[t]{2}{*}{ Cytoplasmic } & @ & & & 0.328 & -0.035 & 0.464 & 0.03 \\
\hline & $p$-Value & & & 0.001 & 0.739 & $<0.0001$ & 0.76 \\
\hline
\end{tabular}

ER: Estrogen receptor; Ki-67: proliferative marker Ki-67; LCOR: ligand-dependent nuclear receptor corepressor; NRIP1: nuclear receptor interacting protein 1; PR: progesterone receptor.

\section{Discussion}

In our study, both NRIP1 and LCOR proteins were expressed in most of the endometrioid endometrial cancer cases (Figure 1). Overall, these proteins were moderately expressed predominantly in the cytoplasm. The IRS values for cytoplasmic and nuclear NRIP1 were not correlated with that of cytoplasmic LCOR (data not shown). LCOR was expressed only in the cytoplasm in cancer and control tissues, whereas NRIP1 was distributed in both the cytoplasm and nucleus with a predominant expression in the nucleus (Figure 1). Thus, tumors were characterized by a low nuclear/high cytoplasmic IRS for NRIP1 and high IRS for cytoplasmic LCOR for cancer tissues compared to normal tissues.

According to the statistical analysis, we found that cytoplasmic NRIP1 expression was positively correlated with nuclear NRIP1 expression. Interestingly, the expression of NRIP1 and LCOR follows a parallel pattern of expression in cancer tissues as both were up-regulated in cancer tissues compared to control tissues. Hence, their overexpression may take part in triggering tumorigenesis, but further overexpression of cytoplasmic LCOR may demonstrate a protective role. The majority of tumors expressed both proteins, whereas only a small proportion of cases was negative for both.

The results of our study demonstrate that overexpression of NRIP1 in the nucleus and the cytoplasm was strongly correlated with advanced myometrial invasion, indicating its possible role in tumor aggressiveness (Figure 1). Evaluating correlations between the patients' clinicopathological features and NRIP1 and LCOR IRS values, it was revealed that cytoplasmic LCOR expression was positively correlated with ER and PR expression, while cytoplasmic NRIP1 expression was strongly correlated with nuclear NRIP1 expression, ER and Ki-67. These findings indicate transactivation of estrogen and progesterone signaling pathways from the interaction of both NRIP1 and LCOR co-
Table III. Immunoreactive score (IRS) for expression of liganddependent nuclear receptor corepressor (LCOR) and nuclear receptor interacting protein 1 (NRIP1) according to myometrial invasion.

\begin{tabular}{lcccccc}
\hline Protein & $\begin{array}{c}\text { Myometrial } \\
\text { invasion }\end{array}$ & $\mathrm{N}$ & $\begin{array}{c}\text { Median } \\
\text { IRS }\end{array}$ & $\begin{array}{c}\text { Mean } \\
\text { rank }\end{array}$ & $\begin{array}{c}\text { Sum of } \\
\text { ranks }\end{array}$ & $p$-Value \\
\hline Cytoplasmic & $<50 \%$ & 43 & 1.0 & 46.86 & 2062 & 0.896 \\
LCOR & $>50 \%$ & 48 & 1.0 & 46.17 & 2216 & \\
Nuclear & $<50 \%$ & 43 & 0.0 & 38.77 & 1706 & 0.004 \\
NRIP1 & $>50 \%$ & 48 & 2.0 & 53.58 & 2572 & \\
Cytoplasmic & $<50 \%$ & 43 & 1.0 & 39.42 & 1734.5 & 0.012 \\
NRIP1 & $>50 \%$ & 48 & 2.0 & 52.99 & 2543.5 & \\
\hline
\end{tabular}

Table IV. Immunoreactive score (IRS) for expression of liganddependent nuclear receptor corepressor (LCOR) and nuclear receptor interacting protein 1 (NRIP1) according to tumor grade.

\begin{tabular}{lccccc}
\hline Protein & Grade & $\mathrm{N}$ & $\begin{array}{c}\text { Median } \\
\text { IRS }\end{array}$ & $\begin{array}{c}\text { Mean } \\
\text { rank }\end{array}$ & $p$-Value \\
\hline Cytoplasmic LCOR & 1 & 29 & 2.0 & 57.05 & 0.021 \\
& 2 & 50 & 1.0 & 44.37 & \\
Nuclear NRIP1 & 3 & 14 & 0.0 & 35.57 & \\
& 1 & 29 & 0.0 & 45.5 & 0.902 \\
Cytoplasmic NRIP1 & 2 & 50 & 1.0 & 48.08 & \\
& 3 & 14 & 0.5 & 46.25 & \\
& 2 & 29 & 1.0 & 43.19 & 0.509 \\
& 3 & 14 & 2.0 & 52.93 & \\
\hline
\end{tabular}

regulators, implying a possible role in the biology of endometrioid carcinomas $(18,34)$. Additionally, cytoplasmic LCOR IRS was significantly associated with tumor grade, as lower cytoplasmic LCOR expression was associated with higher grade (Figure 2), suggesting that higher expression of LCOR may play a role in tumor aggressiveness. According 


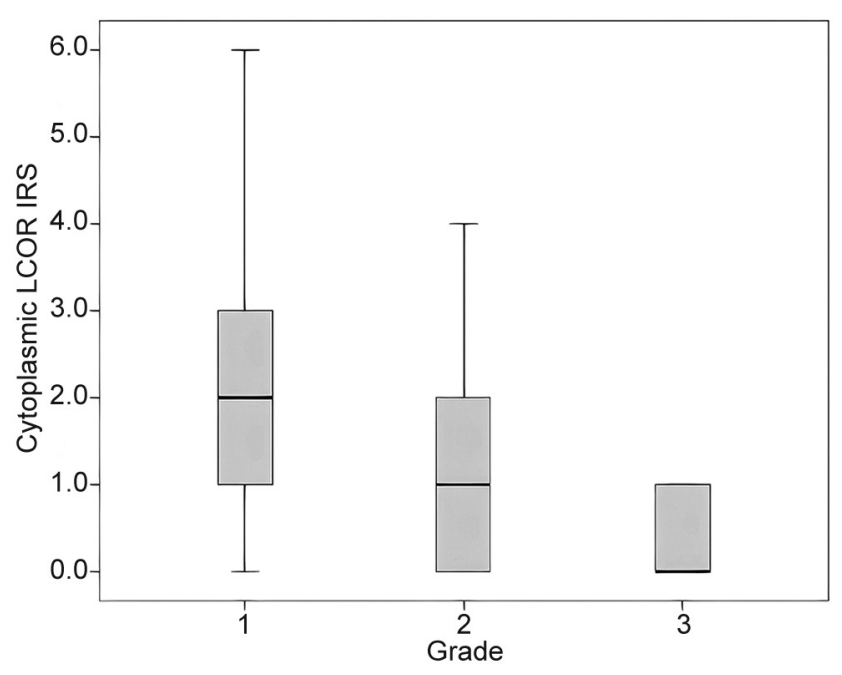

Figure 2. Boxplot of the immunoreactive score (IRS) for cytoplasmic expression of ligand-dependent co-repressor (LCOR) according to tumor grade in patients with endometrioid endometrial cancer (please also see Table IV).

to $\mathrm{Fu}$ et al. (35) and Alber et al.(36), nucleo-cytoplasmic shuttling or a higher transcriptional activity, followed by transcriptional and post-trascriptional modifications (acetylation, SUMOylation or phosphorylation) of LCOR may explain the cytoplasmic increase in our endometrioid endometrial cancer specimens. Nucleo-cytoplasmic shuttling seems to play a significant role in protein function, transport carriers, regulation of signal transduction, and thereby, in tumor growth $(35,37)$. No association was observed between subcellular NRIP1 expression and tumor grade.

We also observed that NRIP1 was expressed in some stromal cells in many of our cases (Figure 1). We hypothesize that NRIP1 expression may have a potential role in carcinogenesis through the interaction of stromal and epithelial cells, but further studies are undoubtedly needed. Furthermore, Kaplan-Meier analysis demonstrated that high cytoplasmic LCOR expression was associated with longer OS of patients with endometrioid endometrial cancer compared with patients whose tumors expressed low levels (Figure 3). Strikingly, by using multivariate Cox regression analysis, cytoplasmic LCOR expression was found to be an independent positive prognostic biomarker in endometrioid endometrial cancer.

NRIP1 and LCOR are involved in various pathways that are relevant to the development of breast and cervical cancer, such as ER signaling (3, 11, 25, 38). Indeed, increased estrogen levels (through obesity, long-term usage of oral contraceptives or repeated parity) can lead to an increased risk of breast, cervical and endometrial cancer development $(18,20,25)$. NRIP1 directly interacts with HDACs and it has been suggested that this interaction may carry HDACs away
Table V. Overall survival for patients with endometrioid endometrial cancer according to the immunoreactive score (IRS) for expression of ligand-dependent nuclear receptor corepressor (LCOR) and nuclear receptor interacting protein 1 (NRIP1).

\begin{tabular}{llllll}
\hline & & \multicolumn{4}{c}{ Mean, months } \\
\cline { 3 - 5 } Protein & & Estimate & SE & $\begin{array}{c}95 \% \text { Confidence } \\
\text { interval }\end{array}$ & $p$-Value \\
& & & \multicolumn{4}{c}{$45.8-52.7$} & 0.029 \\
\hline Cytoplasmic & Overall & 49.3 & 1.8 & 45.7 & \\
LCOR & IRS $\leq 2$ & 47.6 & 2.2 & $43.2-52.0$ & \\
& IRS $>2$ & 52.8 & 2.9 & $47.1-58.4$ & \\
Nuclear & Overall & 49.3 & 1.8 & $45.8-52.7$ & 0.502 \\
NRIP1 & IRS $\leq 2$ & 49.0 & 2.1 & $44.9-53.1$ & \\
& IRS $>2$ & 50.2 & 3.4 & $43.6-56.8$ & \\
Cytoplasmic & Overall & 49.3 & 1.8 & $45.8-52.7$ & 0.452 \\
NRIP1 & IRS $\leq 2$ & 49.0 & 2.2 & $44.7-53.2$ & \\
& IRS $>2$ & 50.1 & 3.3 & $43.8-56.5$ & \\
\hline
\end{tabular}

SE: Standard error.

from their binding regions, explaining the up-regulation of gene expression from NRIP1 when transcription is regulated by SP1 (9, 39). LCOR may act dependently on or independently from HDAC modes of function and suppress agonist-activated hormonal (ER and PR) receptor signaling $(23,40,41)$. HDAC6 has been found to promote endometrial cancer through the phosphatase and tensin homolog/AKT serine/threonine kinase $1 /$ mechanistic target of rapamycin kinase/signaling pathway (42). Hence, the interaction of HDACs with NRIP1 and LCOR may reveal a potential mechanism of tumor development.

Moreover, NRIP1 has a confirmed influence on the ER pathway, as it inhibits the encoding of EF2 transcription coregulators (43). EF2 co-regulators is assumed to regulate several genes that are involved in cervical and breast cancer (13). Docquier et al. described new subtypes of breast cancer through the different levels of expression of NRIP1 and E2F1 (13). Higher expression of NRIP1 represses the transactivation of EF2-targeted genes, leading to reduction of cell proliferation (reduction of cells in S-phase of the cell cycle) $(13,42,43)$. In endometrial cancer, it has been demonstrated that E2F proteins were significantly overexpressed compared to normal endometrium, except for E2F4 (42). Consequently, this overexpression of E2F proteins was associated with tumorigenesis, drug resistance and clinical outcome $(40,42)$. Further analysis should be conducted to examine the interaction of E2F family proteins with NRIP1 and LCOR in this malignancy and to identify potentially therapeutic targets.

It has been reported that patients with breast cancer whose tumors expressed high levels of nuclear NRIP1 had a better survival rate $(22,24,38)$. Significant correlations of nuclear NRIP1 expression with N-cadherin and CD133 expression 


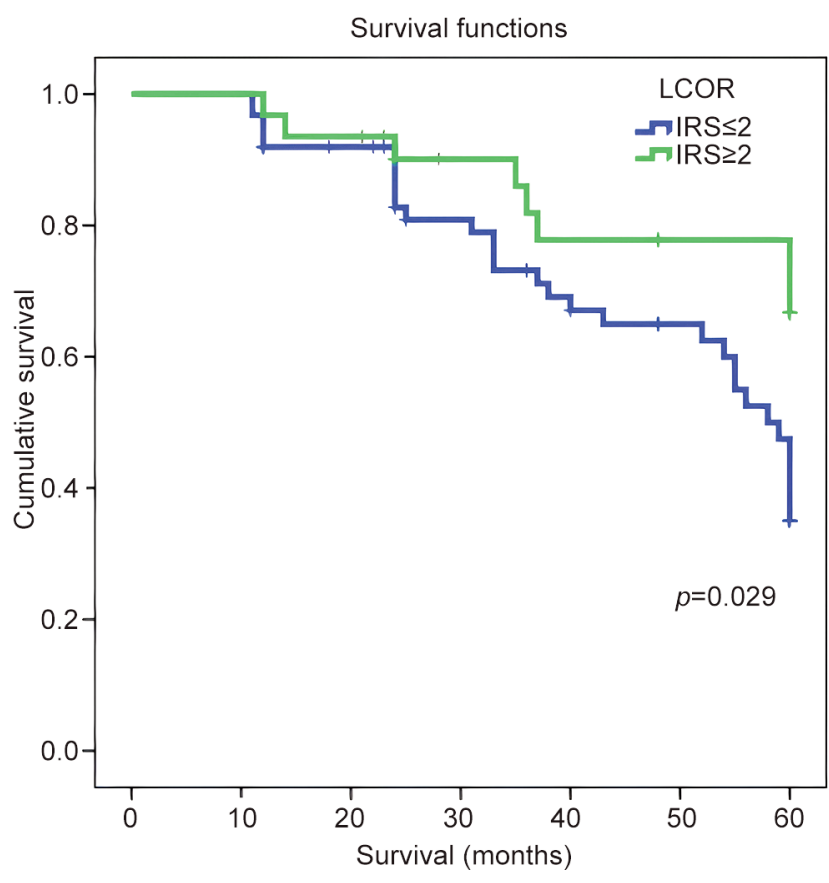

Figure 3. Overall survival for patients with low ( $\leq 2)$ and high $(>2)$ immunoreactive scores for expression of cytoplasmic ligand-dependent co-repressor (LCOR). According to a 60-month follow-up, the OS was longer in patients with high cytoplasmic expression of LCOR. On the contrary, OS in patients with tumors expressing low cytoplasmic LCOR had a poor prognosis.

has also been observed in breast cancer (24). Interestingly, in unifocal breast cancer, LCOR, NRIP1 and ER $\beta$ expression were inversely correlated with OS (22). In cervical cancer, both NRIP1 and LCOR expression were associated with worse survival outcome (25). However, low nuclear expression of LCOR and high nuclear expression of NRIP1 were also associated with higher grade cervical intraepithelial neoplasia, underlying their role in cancer development ( 25 26). The expression of both genes has been found to be down-regulated in colorectal cancer, while in gastric cancer, higher levels of these co-regulators were associated with poor prognosis $(14,44)$. Triki et al. observed strong correlations of NRIP1 and LCOR with E-cadherin and cyclo-oxygenase 2 expression in colorectal cancer (14). Interestingly, in colorectal cancer, a rather antagonistic activity of LCOR and NRIP1 has been reported and low expression of NRIP1 had favorable prognosis, whereas LCOR conferred a dismal prognosis (14). Moreover, it has been demonstrated that NRIP1 overexpression in hepatocellular carcinoma inhibited cell proliferation and migration, whereas down-regulation of NRIP1 promoted tumor growth (45).

These contradictory findings of the differential impact of NRIP1 and LCOR expression in different types of cancer and on patient survival along with our results indicate that these
Table VI. Cox regression analysis of significant histopathological variables.

\begin{tabular}{lccrccc}
\hline Variable & B & SE & Wald & df & $\operatorname{Exp}(\mathrm{B})$ & $p$-Value \\
\hline $\begin{array}{l}\text { Cyt. LCOR } \\
\quad\end{array}$ & & & & & & \\
$\quad$ IRS & -0.428 & 0.142 & 9.053 & 1 & 0.652 & 0.003 \\
ER & & & & & & \\
$\quad$ IRS & 0.156 & 0.063 & 6.098 & 1 & 1.169 & 0.014 \\
Stage & & & 18.013 & 3 & & 0.004 \\
$\quad$ II vs. I & 0.515 & 0.414 & 1.548 & 1 & 1.673 & 0.213 \\
$\quad$ III vs. I & 0.975 & 0.482 & 4.090 & 1 & 2.651 & 0.043 \\
IV vs. I & 3.057 & 0.736 & 17.248 & 1 & 21.254 & $<0.0001$ \\
Grade & & & 15.195 & 2 & & 0.001 \\
$\quad$ 2 vs. 1 & -0.514 & 0.424 & 1.465 & 1 & 0.598 & 0.226 \\
3 vs. 1 & 1.465 & 0.538 & 7.402 & 1 & 4.326 & 0.007 \\
\hline
\end{tabular}

ER: Estrogen receptor; Cyt. LCOR: cytoplasmic ligand-dependent corepressor; IRS: immunoreactive score; NRIP1: nuclear receptor interacting protein.

transcription factors may have much more complex roles and functions in cell growth, proliferation and tumorigenesis. Depending on the physiological or pathophysiological conditions, these co-regulators definitely have a heterogenic activity, and are able to function either as co-repressors or as co-activators (46). More thorough research is essential to decipher their participation in regulation by activating or suppressing crucial oncogenic pathways such as steroid receptors pathways, WNT/APC regulator of WNT signaling pathway/ $\beta$-catenin, T-cell factor signaling, p53, nuclear factor kappa B, Hippo and many others which are also involved in endometrial cancer tumorigenesis $(13,14,22,24,26)$. Additionally, mutations or translocations of the abovementioned genes may have a strong impact on gene expression and remodel the structure of NRIP1 or LCOR proteins, resulting in tumor growth, biological aggressiveness and microsatellite instability $(15,19,47)$.

Our study has several limitations derived from its retrospective nature and the fact that data were collected from a single center. During the study period, treatments may have been modified. However, we used a well-characterized patient cohort and with 5-year follow-up of our patients, we managed to collect valuable prognostic information through the present study.

In conclusion, it is noteworthy to highlight that our study reports, for first time according to our knowledge, the nuclear/cytoplasmic expression of NRIP1 and LCOR in endometrioid endometrial cancer. Correlations of NRIP1 and LCOR protein expression with other clinicopathological characteristics indicate activation of hormonal signaling pathways. Most significantly, we suggest that cytoplasmic LCOR expression may be a potential new independent prognostic marker and the NRIP1/LCOR axis may become a new target for novel therapies in endometrial cancer. 


\section{Conflicts of Interest}

The Authors declare that they have no competing interests. We confirm that the Authors have full control of all primary data and agree that the journal may review these data if requested.

\section{Authors' Contributions}

S. Flindris and A. Goussia designed the study. S. Flindris, A. Goussia, A.C. Lazaris, I. Thymara and N. Katsoulas contributed to the data. I. Navrozoglou, M. Paschopoulos and S. Flindris contributed to the acquisition of the original material and A. Goussia contributed to the examination of the original material. S. Flindris and A.C. Lazaris contributed to the analysis of data. All Authors have read and approved the article.

\section{References}

1 Colombo N, Creutzberg C, Amant F, Bosse T, González-Martín A, Ledermann J, Marth C, Nout R, Querleu D, Mirza MR, Sessa $\mathrm{C}$ and ESMO-ESGO-ESTRO Endometrial Consensus Conference Working Group: ESMO-ESGO-ESTRO consensus conference on endometrial cancer: diagnosis, treatment and follow-up. Int J Gynecol Cancer 26(1): 2-30, 2016. PMID: 26645990. DOI: 10.1097/IGC.0000000000000609

2 Hamilton CA, Pothuri B, Arend RC, Backes FJ, Gehrig PA, Soliman PT, Thompson JS, Urban RR and Burke WM: Endometrial cancer: A society of gynecologic oncology evidence-based review and recommendations, part II. Gynecol Oncol 160(3): 827-834, 2021. PMID: 33451724. DOI: 10.1016/j.ygyno.2020.12.024

$3 \mathrm{Lu} \mathrm{KH}$ and Broaddus RR: Endometrial cancer. N Engl J Med 383(21): 2053-2064, 2020. PMID: 33207095. DOI: 10.1056/ NEJMra1514010

4 Rohira AD and Lonard DM: Steroid receptor coactivators present a unique opportunity for drug development in hormonedependent cancers. Biochem Pharmacol 140: 1-7, 2017. PMID: 28390937. DOI: 10.1016/j.bcp.2017.04.005

5 Kiskinis E, Chatzeli L, Curry E, Kaforou M, Frontini A, Cinti S, Montana G, Parker MG and Christian M: RIP140 represses the "brown-in-white" adipocyte program including a futile cycle of triacylglycerol breakdown and synthesis. Mol Endocrinol 28(3): 344-356, 2014. PMID: 24479876. DOI: 10.1210/me.2013-1254

6 Christian M, Kiskinis E, Debevec D, Leonardsson G, White R and Parker MG: RIP140-targeted repression of gene expression in adipocytes. Mol Cell Biol 25(21): 9383-9391, 2005. PMID: 16227589. DOI: $10.1128 / \mathrm{MCB} .25 .21 .9383-9391.2005$

7 White JH, Fernandes I, Mader S and Yang XJ: Corepressor recruitment by agonist-bound nuclear receptors. Vitam Horm 68 : 123-143, 2004. PMID: 15193453. DOI: $10.1016 / \mathrm{S} 0083-$ 6729(04)68004-6

8 Watson PJ, Fairall L and Schwabe JW: Nuclear hormone receptor co-repressors: structure and function. Mol Cell Endocrinol 348(2): 440-449, 2012. PMID: 21925568. DOI: 10.1016/j.mce.2011.08.033

9 Augereau P, Badia E, Balaguer P, Carascossa S, Castet A, Jalaguier $S$ and Cavaillès $V$ : Negative regulation of hormone signaling by RIP140. J Steroid Biochem Mol Biol 102(1-5): 5159, 2006. PMID: 17056252. DOI: 10.1016/j.jsbmb.2006.09.005
10 Aziz MH, Chen X, Zhang Q, DeFrain C, Osland J, Luo Y, Shi $\mathrm{X}$ and Yuan R: Suppressing NRIP1 inhibits growth of breast cancer cells in vitro and in vivo. Oncotarget 6(37): 39714-39724, 2015. PMID: 26492163. DOI: 10.18632/oncotarget.5356

11 Jalaguier S, Teyssier C, Nait Achour T, Lucas A, Bonnet S, Rodriguez C, Elarouci N, Lapierre M and Cavaillès V: Complex regulation of LCoR signaling in breast cancer cells. Oncogene 36(33): 4790-4801, 2017. PMID: 28414308. DOI: 10.1038/onc. 2017.97

12 Lei JJ, Peng RJ, Kuang BH, Yuan ZY, Qin T, Liu WS, Guo YM, Han HQ, Lian YF, Deng CC, Zhang HJ, Chen LZ, Feng QS, Xu M, Feng L, Bei JX and Zeng YX: NOP14 suppresses breast cancer progression by inhibiting NRIP1/Wnt/ $\beta$-catenin pathway. Oncotarget 6(28): 25701-25714, 2015. PMID: 26213846. DOI: 10.18632 /oncotarget.4573

13 Docquier A, Harmand PO, Fritsch S, Chanrion M, Darbon JM and Cavaillès V: The transcriptional coregulator RIP140 represses E2F1 activity and discriminates breast cancer subtypes. Clin Cancer Res 16(11): 2959-2970, 2010. PMID: 20410059. DOI: 10.1158/1078-0432.CCR-09-3153

14 Triki M, Ben Ayed-Guerfali D, Saguem I, Charfi S, Ayedi L, Sellami-Boudawara T, Cavailles V and Mokdad-Gargouri R: RIP140 and LCoR expression in gastrointestinal cancers. Oncotarget 8(67): 111161-111175, 2017. PMID: 29340045. DOI: 10.18632/oncotarget.22686

15 Lapierre M, Castet-Nicolas A, Gitenay D, Jalaguier S, Teyssier $\mathrm{C}$, Bret $\mathrm{C}$, Cartron $\mathrm{G}$, Moreaux $\mathrm{J}$ and Cavaillès V: Expression and role of RIP140/NRIP1 in chronic lymphocytic leukemia. J Hematol Oncol 8: 20, 2015. PMID: 25879677. DOI: 10.1186/ s13045-015-0116-6

16 Liang Y, Lin B, Ye Z, Chen S, Yu H, Chen C, Zhang X, Zhou K and Zeng J: Triple-high expression of phosphatase and tensin homolog (PTEN), estrogen receptor (ER) and progesterone receptor (PR) may predict favorable prognosis for patients with Type I endometrial carcinoma. J Cancer 11(6): 1436-1445, 2020. PMID: 32047550. DOI: 10.7150/jca.33720

17 Luo L, Xu L and Tang L: The expression of ER, PR in endometrial cancer and analysis of their correlation with ERK signaling pathway. Cancer Biomark 21(1): 145-149, 2017. PMID: 29081408. DOI: 10.3233/CBM-170457

18 Smith D, Stewart CJR, Clarke EM, Lose F, Davies C, Armes J, Obermair A, Brennan D, Webb PM, Nagle CM and Spurdle AB: ER and PR expression and survival after endometrial cancer. Gynecol Oncol 148(2): 258-266, 2018. PMID: 29217139. DOI: 10.1016/j.ygyno.2017.11.027

19 Ferreira AM, Tuominen I, Sousa S, Gerbens F, van Dijk-Bos K, Osinga J, Kooi KA, Sanjabi B, Esendam C, Oliveira C, Terpstra P, Hardonk M, van der Sluis T, Zazula M, Stachura J, van der Zee AG, Hollema H, Sijmons RH, Aaltonen LA, Seruca R, Hofstra RM and Westers $\mathrm{H}$ : New target genes in endometrial tumors show a role for the estrogen-receptor pathway in microsatellite-unstable cancers. Hum Mutat 35(12): 1514-1523, 2014. PMID: 25231886. DOI: 10.1002/humu.22700

20 Rosell M, Nevedomskaya E, Stelloo S, Nautiyal J, Poliandri A, Steel JH, Wessels LF, Carroll JS, Parker MG and Zwart W: Complex formation and function of estrogen receptor $\alpha$ in transcription requires RIP140. Cancer Res 74(19): 5469-5479, 2014. PMID: 25145671. DOI: 10.1158/0008-5472.CAN-13-3429

21 Docquier A, Garcia A, Savatier J, Boulahtouf A, Bonnet S, Bellet V, Busson M, Margeat E, Jalaguier S, Royer C, Balaguer P and 
Cavaillès V: Negative regulation of estrogen signaling by ER $\beta$ and RIP140 in ovarian cancer cells. Mol Endocrinol 27(9): 14291441, 2013. PMID: 23885094. DOI: 10.1210/me.2012-1351

22 Müller K, Sixou S, Kuhn C, Jalaguier S, Mayr D, Ditsch N, Weissenbacher T, Harbeck N, Mahner S, Cavaillès V and Jeschke U: Prognostic relevance of RIP140 and ER $\beta$ expression in unifocal versus multifocal breast cancers: a preliminary report. Int J Mol Sci 20(2): 418, 2019. PMID: 30669416. DOI: 10.3390/ijms20020418

23 Palijan A, Fernandes I, Verway M, Kourelis M, Bastien Y, Tavera-Mendoza LE, Sacheli A, Bourdeau V, Mader S and White JH: Ligand-dependent corepressor LCoR is an attenuator of progesterone-regulated gene expression. J Biol Chem 284(44): 30275-30287, 2009. PMID: 19744932. DOI: 10.1074/jbc.M109. 051201

24 Sixou S, Müller K, Jalaguier S, Kuhn C, Harbeck N, Mayr D, Engel J, Jeschke U, Ditsch $\mathrm{N}$ and Cavaillès V: Importance of RIP140 and LCoR sub-cellular localization for their association with breast cancer aggressiveness and patient survival. Transl Oncol 11(5): 1090-1096, 2018. PMID: 30007204. DOI: 10.1016/ j.tranon.2018.06.006

25 Vattai A, Cavailles V, Sixou S, Beyer S, Kuhn C, Peryanova M, Heidegger H, Hermelink K, Mayr D, Mahner S, Dannecker C, Jeschke U and Kost B: Investigation of RIP140 and LCoR as independent markers for poor prognosis in cervical cancer. Oncotarget 8(62): 105356-105371, 2017. PMID: 29285256. DOI: $10.18632 /$ oncotarget.22187

26 Vogelsang TLR, Schmoeckel E, Kuhn C, Blankenstein T, Temelkov M, Heidegger H, Kolben TM, Kolben T, Mahner S, Mayr D, Jeschke U and Vattai A: Regulation of LCoR and RIP140 expression in cervical intraepithelial neoplasia and correlation with CIN progression and dedifferentiation. J Cancer Res Clin Oncol 146(7): 1847-1855, 2020. PMID: 32157438. DOI: $10.1007 / \mathrm{s} 00432-020-03178-\mathrm{x}$

27 Asim M, Hafeez BB, Siddiqui IA, Gerlach C, Patz M, Mukhtar $\mathrm{H}$ and Baniahmad A: Ligand-dependent corepressor acts as a novel androgen receptor corepressor, inhibits prostate cancer growth, and is functionally inactivated by the Src protein kinase. J Biol Chem 286(43): 37108-37117, 2011 PMID: 21856747. DOI: $10.1074 /$ jbc.M111.292771

28 Song Y, Shan S, Zhang Y, Liu W, Ding W, Ren W, Xia H, Li X, Zhang Q, Zhao L, Li X, Yan J and Ying H: Ligand-dependent corepressor acts as a novel corepressor of thyroid hormone receptor and represses hepatic lipogenesis in mice. J Hepatol 56(1): 248-254, 2012. PMID: 21827732. DOI: 10.1016/j.jhep. 2011.07.014

29 Calderon MR, Verway M, An BS, DiFeo A, Bismar TA, Ann DK, Martignetti JA, Shalom-Barak T and White JH: Liganddependent corepressor (LCoR) recruitment by Kruppel-like factor 6 (KLF6) regulates expression of the cyclin-dependent kinase inhibitor CDKN1A gene. J Biol Chem 287(12): 86628674, 2012. PMID: 22277651. DOI: 10.1074/jbc.M111.311605

30 Fernandes I, Bastien Y, Wai T, Nygard K, Lin R, Cormier O, Lee HS, Eng F, Bertos NR, Pelletier N, Mader S, Han VK, Yang XJ and White JH: Ligand-dependent nuclear receptor corepressor LCoR functions by histone deacetylase-dependent and independent mechanisms. Mol Cell 11(1): 139-150, 2003. PMID: 12535528. DOI: 10.1016/s1097-2765(03)00014-5

31 Celià-Terrassa T, Liu DD, Choudhury A, Hang X, Wei Y, Zamalloa J, Alfaro-Aco R, Chakrabarti R, Jiang YZ, Koh BI,
Smith HA, DeCoste C, Li JJ, Shao ZM and Kang Y: Normal and cancerous mammary stem cells evade interferon-induced constraint through the miR-199a-LCOR axis. Nat Cell Biol 19(6): 711-723, 2017. PMID: 28530657. DOI: $10.1038 / \mathrm{ncb} 3533$

32 Amant F, Mirza MR, Koskas M and Creutzberg CL: Cancer of the corpus uteri. Int J Gynaecol Obstet 143 Suppl 2: 37-50, 2018. PMID: 30306580. DOI: 10.1002/ijgo.12612

33 Colombo N, Preti E, Landoni F, Carinelli S, Colombo A, Marini C, Sessa C and ESMO Guidelines Working Group: Endometrial cancer: ESMO Clinical Practice Guidelines for diagnosis, treatment and follow-up. Ann Oncol 24 Suppl 6: vi33-vi38, 2013. PMID: 24078661. DOI: 10.1093/annonc/mdt353

34 Guan J, Xie L, Luo X, Yang B, Zhang H, Zhu Q and Chen X: The prognostic significance of estrogen and progesterone receptors in grade I and II endometrioid endometrial adenocarcinoma: hormone receptors in risk stratification. J Gynecol Oncol 30(1): e13, 2019. PMID: 30479097. DOI: 10.3802/jgo.2019.30.e13

35 Fu X, Liang C, Li F, Wang L, Wu X, Lu A, Xiao G and Zhang G: The Rules and Functions of Nucleocytoplasmic Shuttling Proteins. Int J Mol Sci 19(5): 1445, 2018. PMID: 29757215. DOI: $10.3390 /$ ijms 19051445

36 Alber F, Dokudovskaya S, Veenhoff LM, Zhang W, Kipper J, Devos D, Suprapto A, Karni-Schmidt O, Williams R, Chait BT, Sali A and Rout MP: The molecular architecture of the nuclear pore complex. Nature 450(7170): 695-701, 2007. PMID: 18046406. DOI: 10.1038 /nature06405

37 Shreberk-Shaked M and Oren M: New insights into YAP/TAZ nucleo-cytoplasmic shuttling: new cancer therapeutic opportunities? Mol Oncol 13(6): 1335-1341, 2019. PMID: 31050214. DOI: 10.1002/1878-0261.12498

38 Kaipparettu BA, Malik S, Konduri SD, Liu W, Rokavec M, van der Kuip H, Hoppe R, Hammerich-Hille S, Fritz P, Schroth W, Abele I, Das GM, Oesterreich S and Brauch H: Estrogenmediated downregulation of CD24 in breast cancer cells. Int J Cancer 123(1): 66-72, 2008. PMID: 18404683. DOI: 10.1002/ ijc. 23480

39 Augereau P, Badia E, Carascossa S, Castet A, Fritsch S, Harmand PO, Jalaguier S and Cavaillès V: The nuclear receptor transcriptional coregulator RIP140. Nucl Recept Signal 4: e024, 2006. PMID: 17088940. DOI: 10.1621/nrs.04024

$40 \mathrm{Hu} \mathrm{J}$, Shen J and Sun J: CDK4/RB/E2Fs axis as potential therapeutic target of endometrial cancer. Biomed Pharmacother 125: 109870, 2020. PMID: 32032891. DOI: 10.1016/ j.biopha. 2020.109870

41 Palijan A, Fernandes I, Bastien Y, Tang L, Verway M, Kourelis M, Tavera-Mendoza LE, Li Z, Bourdeau V, Mader S, Yang XJ and White JH: Function of histone deacetylase 6 as a cofactor of nuclear receptor coregulator LCoR. J Biol Chem 284(44): 30264-30274, 2009. PMID: 19744931. DOI: 10.1074/jbc. M109.045526

42 Zhang Y, Wang Z, Ma J, Huo J, Li Y, Wang Y, Chen H, Shan L and Ma X: Bioinformatics Identification of the Expression and Clinical Significance of E2F Family in Endometrial Cancer. Front Genet 11: 557188, 2020. PMID: 33329696. DOI: $10.3389 /$ fgene. 2020.557188

43 Lapierre M, Docquier A, Castet-Nicolas A, Gitenay D, Jalaguier $\mathrm{S}$, Teyssier $\mathrm{C}$ and Cavaillès $\mathrm{V}$ : The emerging role of the transcriptional coregulator RIP140 in solid tumors. Biochim 
Biophys Acta 1856(1): 144-150, 2015. PMID: 26116758. DOI: 10.1016/j.bbcan.2015.06.006

44 Fang D and Lu G: Expression and role of nuclear receptorinteracting protein 1 (NRIP1) in stomach adenocarcinoma. Ann Transl Med 8(20): 1293, 2020. PMID: 33209873. DOI: 10.21037/atm-20-6197

45 Zhang D, Wang Y, Dai Y, Wang J, Suo T, Pan H, Liu H, Shen S and Liu H: Downregulation of RIP140 in hepatocellular carcinoma promoted the growth and migration of the cancer cells. Tumour Biol 36(3): 2077-2085, 2015. PMID: 25391428. DOI: $10.1007 / \mathrm{s} 13277-014-2815-\mathrm{y}$

46 Battaglia S, Maguire O and Campbell MJ: Transcription factor co-repressors in cancer biology: roles and targeting. Int J Cancer 126(11): 2511-2519, 2010. PMID: 20091860. DOI: 10.1002/ijc. 25181
47 Sinclair PB, Blair HH, Ryan SL, Buechler L, Cheng J, Clayton J, Hanna R, Hollern S, Hawking Z, Bashton M, Schwab CJ, Jones L, Russell LJ, Marr H, Carey P, Halsey C, Heidenreich O, Moorman AV and Harrison CJ: Dynamic clonal progression in xenografts of acute lymphoblastic leukemia with intrachromosomal amplification of chromosome 21. Haematologica 103(4): 634-644, 2018. PMID: 29449437. DOI: 10.3324/haematol.2017.172304

Received May 7, 2021

Revised June 15, 2021

Accepted June 24, 2021 